\title{
Application of Environmental DNA (eDNA) Metabarcoding Method to Identify Threatened Sulawesi Mammal Based on 12S rRNA Gene
}

\author{
Bambang Suryobroto*, Ahmad Abdul Jabbar, Puji Rianti \\ Department of Biology, Faculty of Mathematics and Natural Sciences, IPB University, Bogor, Indonesia
}

ARTICLE INFO

Article history:

Received September 17, 2021

Received in revised form October 25, 2021

Accepted November 11, 2021

KEYWORDS:

12s rRNA,

eDNA,

mammals,

metabarcoding,

natural salt-licks

\begin{abstract}
Species detection and identification is a crucial steps in biodiversity assessment. Traditional methods are often invasive and resource intensive. The number of studies demonstrating successful of eDNA metabarcoding approach in species identification has increased rapidly in recent years. Some of large terrestrial mammals have reportedly utilize natural salt licks as a source of minerals in the diet and its genetic material left in the environment can be used to identify species from this site. An eDNA metabarcoding protocol had been carried out to identify Sulawesi mammals from Adudu natural salt-licks, Nantu Wildlife Reserve, Gorontalo. Environmental DNA were extracted from water samples, Amplicon libraries were prepared by PCR amplification and Illumina MiSeq high throughput sequencing. Reads processing and taxonomic assignment carried out in two bioinformatics packages, PipeCraft-1.0 and OBITools-2.11. Two endangered Sulawesi mammals species had been identified, i.e. lowland anoa (Bubalus depressicornis) and babirusa (Babyrousa babyrussa). The accuracy of mammal species identification using eDNA metabarcoding is affected by rigorous experimental procedures, DNA marker reliability, and availability of reference sequence database.
\end{abstract}

\section{Introduction}

Sulawesi has a high endemism of mammal species (Whitten et al. 1987a). At least 79 (62\%) of 127 mammals species (62\%) are endemic to this largest Wallacea ecoregion (Whitten et al. 1987b). Some of these endemic mammals are Endangered e.g. lowland anoa (Bubalus depressicornis) (Burton et al. 2016). However, population decrease is mainly caused by habitat destruction (Margono et al. 2014), wildlife trade, and hunting for bush meat (Lee et al. 2005; O'Brien and Kinnaird 1996). Facing such challenges, studies on Sulawesi mammals are urgently required.

Assessing mammals diversity is the key action on research and conservation with detection and identification as the most important first stages in plotting their distribution in a natural habitats (Hendry et al. 2010). The effectiveness and efficiency of traditional approaches varies in the scope of taxon, time, and the extent of spatial coverage (Campbell et al. 2011). The camera trap method is one that is widely used to detect the presence of species, especially from large groups of mammals (Ahumada

\footnotetext{
* Corresponding Author

E-mail Address: suryobroto@apps.ipb.ac.id
}

et al. 2011). In a broad survey, the camera trap method requires relatively large resources, long periods of time, and limited reach ( $\mathrm{Qu}$ and Stewart 2017). For instance, Janecka et al. (2011) found only seven individuals of snow leopard (Panthera uncia) from a camera trap survey conducted for 65 days in the Gobi Desert, Mongolia. These results contrast with those obtained from a non-invasive molecular approach that successfully detects five individuals within two days.

The non-invasive metabarcoding approach utilizing genetic material found in the environment (eDNA) helps to species identification without contact with the target organisms. This e DNA comes from cellular or extracellular DNA from various organisms exposed to water, soil, and air, hence, it contains information that can be used for multi-species identification (Taberlet et al. 2012). In addition, eDNA metabarcoding allows identification to be carried out more quickly with extensive taxon coverage on a large scale survey (Calvignac-Spencer et al. 2013). Environmental DNA metabarcoding has also been used to estimate the occurrence and abundance of species as in the amphibian groups (Ficetola et al. 2008), aquatic mammal (Foote et al. 2012), and terrestrial mammals (Ushio et al. 2016). 
Mammals reportedly utilize natural licks as a source of essential minerals, particularly sodium which is not sufficiently available in feed plants (Ayotte et al. 2006). Ishige et al. (2017) used the 12S rRNA mitochondrial DNA fragments as a markers for identification of mammal from water sample at a natural salt-licks in Deramakot, Sabah, Malaysia. We observed (14 to 16 September 2017) Adudu natural sal-lick, Nantu Wildlife Reserve, Gorontalo [=Province] (Figure 1) functioned as a gathering point of groups of mammals, thus eDNA can probably be found and used to detect and identify the presence of mammals. Furthermore, this study aims to evaluate the effectiveness of the metabarcoding eDNA approach using 12S rRNA marker and MiMammal primers in the identification of Sulawesi mammal.

\section{Materials and Methods}

\subsection{Tools and Materials}

The materials were used including DNeasy Blood and Tissue kit (Qiagen, Hilden, Germany), 3-ml RNAlater (Thermo Fisher Scientific, MA, USA), $20-\mu \mathrm{L}$ L solution of proteinase-K solution, $220-\mu \mathrm{L}$ L PBS solution (phosphate buffered saline), and 200- $\mu \mathrm{L}$ AL AL buffer solution. DNe blood and tissue purification kit (Qiagen, GmbH, Hilden, Germany), $-\mu$ L solution $L 2 \times$ KAPA HiFi HotStart Ready Mix (KAPA Biosystems, Wilmington, WA, USA), 2.6- $\mu$ L sterilized $\mathrm{L}_{2} \mathrm{O}$ solution, 2- $\mu \mathrm{L}$ L solution DNA template. The MiMammal mix PCR primer (Ushio et al. 2016) consists of MiMammal-U (forward = GGG TTG GTA AAT TTC GTG CCA GC; reverse = CAT AGT GGG GTA

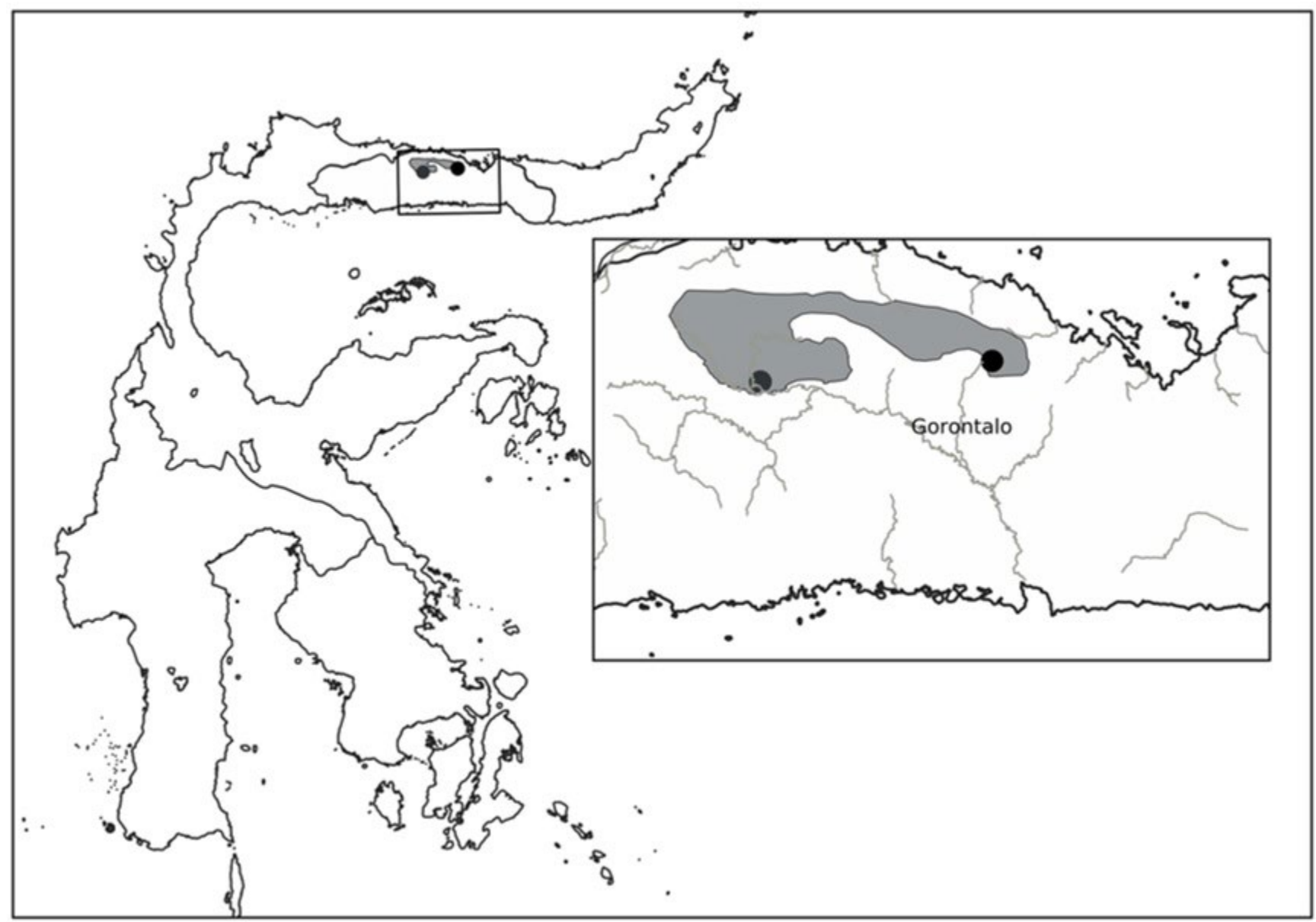

Figure 1. Sampling location at Adudu natural salt-licks, Nantu Wildlife Reserve, Gorontalo (point on a grey area) 
TCT AAT CCC AGT TTG), MiMammal-E (forward = GGA CTG GTC AAT TTC GTG CCA GC; reverse = CAT AGT GAG GTA TCT AAT CTC AGT TTG), and MiMammal-B (forward = GGG TTG GTT AAT TTC GTG CCA GC; reverse $=$ CAT AGT GGG GTA TCT AAT CCC AGT TTG). MiMammal Primer designed to refer to the region (gene region) 12S rRNA mammalian mitochondrial genome (median insert length $=\sim 171 \mathrm{pb}$ ).

The tools used were GPS receivers (GPS Map CSx; Garmin, Ltd), filter (syringe) with 0.2 um pore size (Whatman, New Jersey, USA), Camera Traps with an infrared trigger system (Camera Sensor Fieldnote II, Marif Co. Ltd., Yamaguchi, Japan), 50-ml sterile syringes (Thermo Co. Tokyo, Japan) $0.22-\mu \mathrm{L}$ solution cartridge filter Sterivex (Millipore, MA, USA). The Next Generation Sequencing (NGS) machine Illumina MiSeq (Illumina, San Diego, CA, USA).

\subsection{Camera Trap}

As a supportive to eDNA metabarcoding, five camera trap units (Ltl Acorn 6310W) installed at 5 points around sampling location for 3 days during the period of sampling. The camera shot every 15 minutes or every sensor detect the presence of passing animals. In addition to camera traps, direct observation and identification of traces or other marks are also carried out.

\subsection{Water Sampling and eDNA Extraction}

Refer to Strickler et al. (2015), at least there are three broad categories that potentially influence eDNA persistence, i.e. characteristics of the DNA molecule, abiotic environmental characteristics, and biotic environmental characteristics. DNA can exist in extremely different lengths, sequences, and conformations, and each of these characteristics influence how DNA interacts with its environment and degrades over time. Several studies demonstrate that DNA can persist in freshwater environment less than one month (Dejean et al. 2011) or $<1$ to 54 days (Strickler et al. 2015).

Water samples are taken from five points in one sampling location. Eleven samples with a volume of 2 $\mathrm{ml}$ each were obtained by filtering $400-500 \mathrm{ml}$ water in Adudu natural salt-licks using sterile syringes (Terumo Co., Tokyo, Japan) and Sterivex 0.22- $\mu \mathrm{L}$ filter cartridge (Millipore, MA, USA). Subsequently, 3 $\mathrm{ml}$ of RNAlater (Thermo Fisher Scientific, MA, USA) was added into the cartridge and then stored in the sample bag until extraction eDNA was done.
Extraction of eDNA from the cartridge was done using DNeasy Blood and Tissue kit (Qiagen, Hilden, Germany). Before the lysis process, $20 \mu \mathrm{L}$ of proteinase-K, $220 \mu \mathrm{L}$ PBS (Phosphate Buffered Saline), and $200 \mu \mathrm{L}$ of buffer AL were mixed and added to the Sterivex filter. Furthermore, the Sterivex filter was placed on a rotary shaker inside the incubator at $56^{\circ} \mathrm{C}$ and vibrated at a speed of $20 \mathrm{rpm}$ for 20 minutes. After incubation, the Sterivex filter was centrifuged at $5,000 \mathrm{~g}$ for 1 minutes to collect DNA. Then the DNA was purified using DNeasy blood and tissue purification kit (Qiagen, GmbH, Hilden, Germany) followed the factory protocol.

\subsection{Amplicon Library Preparation and Sequencing}

The first PCR reaction amplifies the target area of 12S rRNA using MiMammal-mix primer. The PCR volume $(12 \mu \mathrm{L})$ consisted of $6 \mu \mathrm{L} 2 \times$ KAPA HiFi HotStart Ready Mix (KAPA Biosystems, Wilmington, WA, USA), $0.7 \mu \mathrm{L}$ of each primer $(5 \mu \mathrm{L}), 2.6 \mu \mathrm{L}$ of sterile $\mathrm{H}_{2} \mathrm{O}$, and $2 \mu \mathrm{L}$ of DNA template. Final concentration of each primer (MiMammal-U/E/B) was $0.3 \mu \mathrm{L}(0.9 \mu \mathrm{L}$ total concentration). The PCR reaction was programmed with a $95^{\circ} \mathrm{C}$ initial denaturation for 3 minutes, followed by 35 cycles of denaturation at $98^{\circ} \mathrm{C}$ for 20 seconds, annealing on temperature of $65^{\circ} \mathrm{C}$ for 15 seconds, extension at $72^{\circ} \mathrm{C}$ for 15 seconds and final extension on $72^{\circ} \mathrm{C}$ for 5 minutes. The PCR product was then purified using AMPure XP solution beads $(\times 0.8)$ (Beckman Coulter, Brea, CA, USA). Ten times dilution of first PCR product was used in indexing process using adapter and dual index of MiSeq Illumina.

The final volume of PCR index reaction $(24 \mu \mathrm{L})$ consists of $12 \mu \mathrm{L} \times$ KAPA HiFi HotStart Ready Mix (KAPA Biosystems, Wilmington, WA, USA), $1.4 \mu \mathrm{L}$ of each primer $(5 \mu \mathrm{L}), 7.2 \mu \mathrm{L}$ of sterile $\mathrm{H}_{2} \mathrm{O}$, and $2 \mu \mathrm{L}$ of the first PCR product. The PCR reaction was programmed under conditions $95^{\circ} \mathrm{C}$ initial denaturation for 3 minutes, followed by 12 cycles of denaturation at $98^{\circ} \mathrm{C}$ for 20 seconds, annealing and extension at $72^{\circ} \mathrm{C}$ for 15 seconds, and extension end at $72^{\circ} \mathrm{C}$ for 5 minutes. The index PCR product was then purified using the AMPure XP solution beads $(\times 0.8)$.

The combined library was selected based on the size of the sequence with a range between 380-400 pb using 2\% E-Gel Size Select agarose gel (Invitrogen, Carlsbad, CA, USA). Furthermore the DNA library was sequenced as paired-end reads using the MiSeq v.2 
Reagent Kit for 150 pb PE on the MiSeq NGS machine (Illumina, San Diego, CA, USA).

\subsection{Amplicon Data Analysis}

The amplicon are processed using two different software package separately to compare each other, PipeCraft-1.0 (Anslan et al. 2017) and OBITools-2.11 (Boyer et al. 2016). The reference sequence of the $12 \mathrm{~S}$ rRNA of mammalian mitochondria genome was downloaded from EMBL directory (ftp.ebi.ac.uk/pub/ databases/embl/release/std) and taxonomic database was downloaded from NCBI (ftp://ftp.ncbi.nih.gov/ pub/taxonomy/taxdump.tar.gz). Reference database compiled using ecoPCR programs (Ficetola et al. 2010).

On the PipeCraft-1.0, the amplicon sequence quality were evaluated using FastQC-0.10.1 program (Andrews 2010). Read pairs using (R1 and R2) were assembled with VSEARCH-2.0.3 (Rognes et al. 2016) with truncqual parameter of 0 , maxee 1 , maxee rate 5 , and minlen 150 . After assembling and renaming the reads, groups file per sample created manually using mothur-1.36.1 (Schloss et al. 2009) because demultiplexing was not done in PipeCraft-1.0. Then de novo chimera filtering was done using VSEARCH-2.0.3 with abundance annotation of 0.97 and database-based filtering using mammalian references mtDNA 12S rRNA database. Amplicon sequence with a frequency of occurance less than the $97 \%$ were discarded and remove from the analysis.

The filtered reads were cutted using mothur-1.36.1 (Schloss et al. 2009) with minimum length $150 \mathrm{pb}$ and maximum length $290 \mathrm{pb}$. The clustering and construction of the OTU (Operational Taxonomical Unit) table using VSEARCH-2.0.3 (Rognes et al. 2016) with a threshold value of 0.97. Taxonomic assignment of the amplicon library was done using blastn algorithm on BLAST+ (Camacho et al. 2009) with E-value of 10 compared to local database of $12 \mathrm{~S}$ rRNA mitochondrial DNA of mammal which was downloaded from EMBL and built using ecoPCR. BLAST hits with the similarity of the sequence of at least $97 \%$ was used to determine a species from each representative sequence. Sequences identity smaller than $97 \%$ are considered as "another sequence". Reads that were incompatible with the mammalian database were considered as contamination and ignored. However, reads that were compatible with the mammal database not found in Sulawesi according to the 2017 IUCN nomenclature considered as "other sequences".

On the OBITools-2.11 (Boyer et al. 2016), amplicon sequences were assembled first using the "illuminapairedend" command separately for each couple of files (R1 and R2), then ngsfilter run on each of the result file with the description as only one line (one sample) with the proper primers and without index. Afterward, "obiannotate" command used on the result of each sample to add a sample tag and then concatenating the results for downstream analysis. Then the "ngsfilter" and "obiannotate" were used to determine the identity of a sample from each amplicon sequence. Dereplication or grouping of the reads identical to unique sequences and comparing all sequences reads to each other in the data set using "obiuniq" command. At this step, all sequences which duplicated were deleted (Seguritan and Rohwer 2001). Reads filtering from sequential variants due to PCR or sequencing errors (chimera and singleton) was done using the "obiclean" command. Afterwards, taxonomic assignment was done using "ecotag" command then "ecotab" command to display the output file into the .csv table.

\section{Results}

Eleven water samples were collected from Adudu salt-licks, only three eDNA of these samples were successfully extracted and were used for amplicon library preparation. This can be caused by the low quantity of eDNAdue to degradation by environmental factors such as ultraviolet radiation, temperature, and $\mathrm{pH}$ as the average eDNA concentration of the first PCR product is $0.05 \mathrm{ng} / \mu \mathrm{l}$ and $230.54 \mathrm{pg} / \mu \mathrm{l}$.

Preprocessing on total reads of Illumina MiSeq sequencing can be seen in Table 1 . The sequencing resulted in 231,571 reads sequence with a length between 151-284 pb. Quality filtering process and merging of R1 and R2 using VSEARCH-2.0.3 generate 131,275 sequences with minimum lenght of $161 \mathrm{bp}$, maximum lenght $252 \mathrm{bp}$, and avarage lenght $232 \mathrm{bp}$, then chimeric filtering obtained 79,927 sequences. 
Table 1. Total reads of Illumina MiSeq and number after pre-processing with two different pipeline

\begin{tabular}{|c|c|c|c|c|}
\hline Pipeline & $\begin{array}{l}\text { Total } \\
\text { reads }\end{array}$ & $\begin{array}{l}\text { Quality } \\
\text { trimming }\end{array}$ & $\begin{array}{l}\text { Unique } \\
\text { sequence }\end{array}$ & $\begin{array}{l}\text { Representative } \\
\text { sequence }\end{array}$ \\
\hline PipeCraft & 231,571 & 131,275 & 79,927 & 7,086 \\
\hline OBITools & 231,571 & 193,606 & 5,342 & 251 \\
\hline
\end{tabular}

Clustering process removed 3,672 clusters that had less than 2 sequences and kept 3,414 clusters with 76,255 sequences, among which 7,086 are representative sequence. Separately, R1 and R2 merging with illuminapairedended on OBITools-2.11 obtained 193,606 reads, 5,342 of which were unique sequences. The filtering process was carried out by obtaining 251 representative sequences.

Both two pipelines (See Table 2) successfully identified the same Sulawesi threatened mammal species, Buru babirusa (Babyrousa babyrussa, Linnaeus, 1758) and Lowland anoa (Bubalus depressicornis). However, the reads aligned to Buru babirusa (B. Babyrussa, Linnaeus, 1758) most likely are false positive, since this species are not naturally distributed in the study site. Buru babirusa occurs on two of the Sula Islands (Mangole and Taliabu) and on Buru island. It is strongly supposed to be identifed as North Sulawesi babirusa (B. celebensis, Deninger, 1910), where the study site is within its geographical range. This species are widely distributed on Sulawesi island, including Muna, Buton and Lembeh island with the exception of the southwestern peninsula. This false positive can occur due to the absence of 12S rRNA reference sequences of $B$. celebensis on GeneBank.

In addition to successfully identifying Sulawesi mammal, taxonomic assignment using OBITools-2.11 found reads aligned to Tonkean macaque (Macaca tonkeana) that is not naturally distributed to the study site. However, as most of another approaches, eDNA metabarcoding is imperfect. It can fail to detect species that are actually exist (false negative), or vice versa, species might be detected in an area that do not actually present. The misidentification may occur due to some possibilities such as contamination while carrying out the laboratory procedures, chimaeras, or sequences observed in just a few reads. These are the main challenges for eDNA metabarcoding analysis. We tried to do best practice in field and laboratory works and used two different pipelines to evaluate the results.

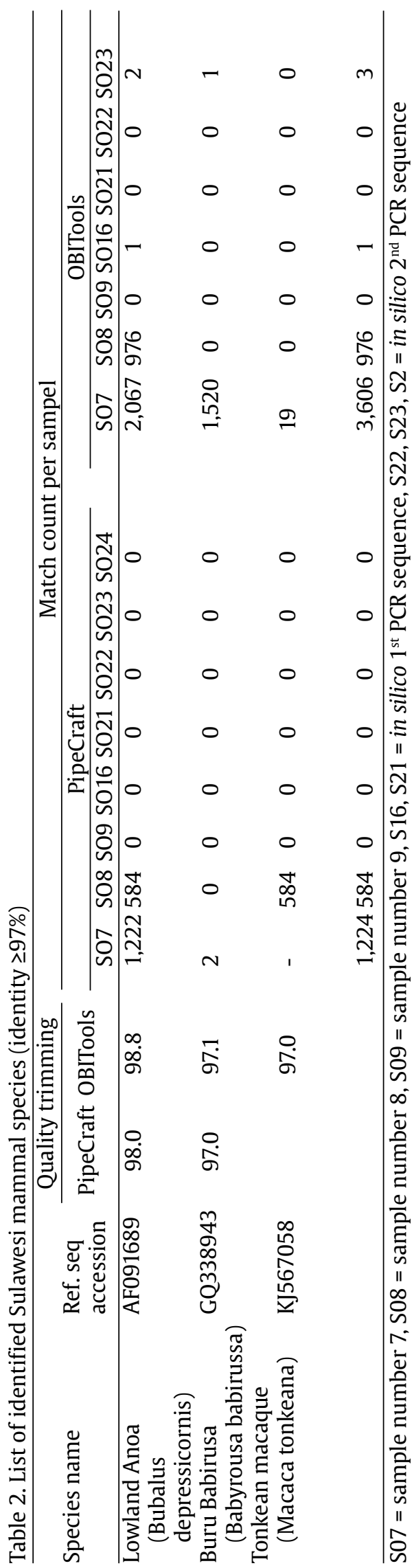




\section{Discussion}

Despite it is not fully perfect, 12S rRNA metabarcoding using eDNA is still reliable for species identification. Referring to Karlsson and Holmlund (2007), the success and accuracy of species identification based on DNA barcoding is determined by the proportion of conserved and variable region of the marker that is used. Conserved region are needed as primary universal binding sites while more variable region allows differentiation of species. The 12S rRNA gene is one of the mtDNA markers widely used for identification of vertebrate species (Melton and Holland 2007). Like other mtDNA genes, 12S rRNA has a large number of copies so that it can minimize errors amplification caused by low eDNA concentration due to the degradation process (Robin and Wong 1988). The loop region of this gene has a high variability whereas the double stranded area is very conserved (Springer and Douzery 1996). Therefore 12S rRNA marker has enough information needed to identify to the species level (Balitzki-
Korte et al. 2005). The MiMammal universal primer is designed to amplify the hypervariable region from mammal mitochondrial DNA 12S rRNA gene (Ushio et al. 2016). The high homology of "other mammal" sequences found in this study probably is caused by a MiMammal primer or PCR reaction conditions are not enough specific for some Sulawesi mammal species.

As supportive information, one of the five camera trap units installed successfully detected the presence of mammals at the Adudu's natural salt-licks, Nantu. Camera traps at point 3 (Figure 2) captured the image of babirusa, this finding confirms the results of detection and identification using eDNA from water samples. However, lowland anoa (B. depressicornis) was not caught on camera even though it had successfully been identified using eDNA metabarcoding. These result shows that eDNA metabarcoding is reliable in identifying threatened Sulawesi mammals. The study of Ishige et al. (2017) also shows that eDNA metabarcoding can detect the presence of mammals though the frequency of camera trap findings is very low.

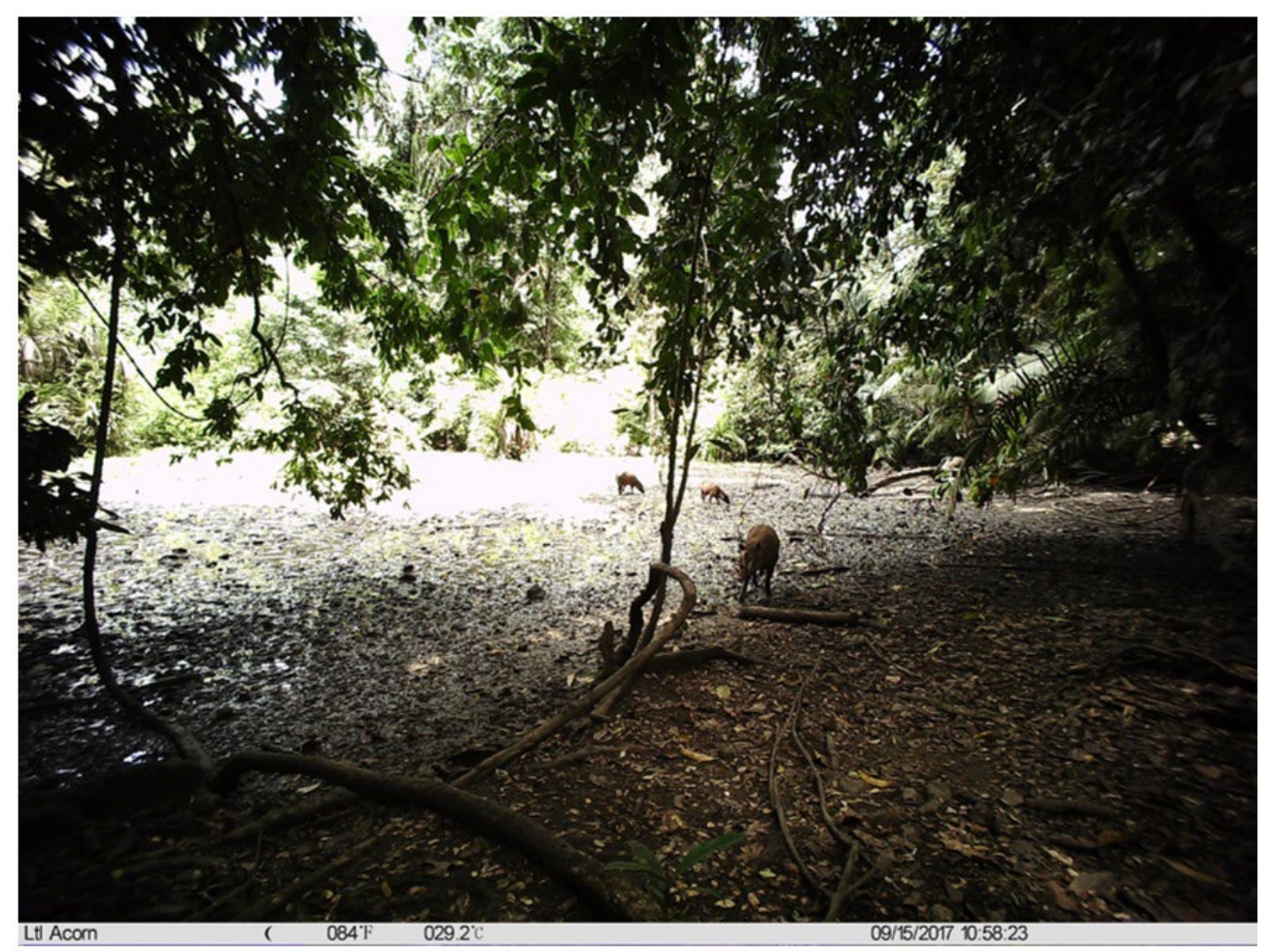

Figure 2. Three individuals of babirusa (B. babyroussa) captured from camera trap number 3 at Adudu natural salt-licks, Nantu Wildlife reserve 


\section{Acknowledgements}

AAJ would like to thank Professors Shiro Koshima, Takushi Kishida and Kei Matsushima of Wildlife Research Center (WRC), Kyoto University for help on learning genome science using JSPS Core-toCore program "International Core of Excellence for Tropical Biodiversity Conservation focusing on Large Animal Studies". We would also like to thank Professor Frédéric Boyer for help and advice on running OBITools-2.11 and Professor Sten Anslan for PipeCraft-1.0. We deeply grateful to head of to head of BKSDA Manado, Agustinus R. Lembang, Head of Kantor BKSDA Wilayah II Gorontalo, Syamsudin Hadju, and Zulham Tangahu. Part of the project is funded by a grant from Ministry of Research and Technology of the Republic of Indonesia (No. 005/ SP2H/LT/DRPM/2021 to BS).

\section{References}

Ahumada, J.A., Silva, C.E., Gajapersad, K., 2011. Community structure and diversity of tropical forest mammals: data from a global camera trap network. Phil. Trans. R. Soc. Biological Sciences, 366, 2703-2711. https://doi. org/10.1098/rstb.2011.0115

Andrews, S., 2010. FastQC: a quality control tool for high throughput sequence data. Available at: http://www. bioinformatics.babraham.ac.uk/projects/fastqc. [Date accessed: 7 August 2018]

Anslan, S., Bahram, M., Hiiesalu, I., Tedersoo, L., 2017. PipeCraft: flexible open-source toolkit for bioinformatics analysis of custom high-throughput amplicon sequencing data. Mol. Ecol. Resour. 17, 234240. https://doi.org/10.1111/1755-0998.12692

Ayotte, B.J., Parker, K.L., Arocena, J.M., Gillingham, M.P., 2006. Chemical composition of lick soils: functions of soil ingestion by four ungulate species. Journal of Mammalogy 87, 878-888. https://doi.org/10.1644/06MAMM-A-055R1.1

Balitzki-Korte, B., Anslinger, K., Bartsch, C., Rolf, B., 2005. Species identification by means of pyrosequencing the mitochondrial 12S rRNA gene. Int. J. Legal Med. 119, 291-294. https://doi.org/10.1007/s00414-0050537-9

Boyer, F., Mercier, C., Bonin, A., Le Bras, Y., Taberlet, P., Coissac, E., 2016. OBITOOLS: a UNIX-inspired software package for DNA metabarcoding. Mol. Ecol. Resour. 16, 176-182. https://doi.org/10.1111/1755-0998.12428

Burton, J., Wheeler, P., Mustari, A., 2016. Bubalus depressicornis. The IUCN Red List of Threatened Species 2016: e.T3126A46364222. https://doi. org/10.2305/IUCN.UK.2016-2.RLTS.T3126A46364222. en

Calvignac-Spencer, S., Merkel, K., Kutzner, N., Kuhl, H., Boesch, C., Kappeler, P.M., Metzger, S., Schubert, G,, Leendert, F., 2013. Carrion fly-derived DNA as a tool for comprehensive and cost-effective assessment of mammalian biodiversity. Molecular. Ecology. 3, 2-10. https://doi.org/10.1111/mec.12183

Camacho, C., Coulouris, G., Avagyan, V., Ma, N., Papadopoulos, J., Bealer, K., Madden, T.L., 2009. BLAST+: architecture and applications. BMC. Bioinf. 10, 421. https://doi. org/10.1186/1471-2105-10-421
Campbell, G. Kuehl, H., Diarrassouba, A., N'Goran, P.K. Boesch, C., 2011. Long-term research sites as refugia for threatened and over-harvested species. Biol. Lett. 7, 723-726. https://doi.org/10.1098/rsbl.2011.0155

Dejean, T., Valentini, A., Duparc, A., Pellier-Cuit, S., Pompanon, F., 2011. Persistence of environmental DNA in freshwater ecosystems. PLoS. ONE. 6, e23398. https:// doi.org/10.1371/journal.pone.0023398

Ficetola, G.F., Miaud, C., Pompanon, F., Taberlet, P., 2008. Species detection using environmental DNA from water samples. Biol. Lett. 4, 423-425. https://doi. org/10.1098/rsbl.2008.0118

Ficetola, G.F., Coissac, E., Zundel, S., 2010. An in silico approach for the evaluation of DNA barcodes. BMC. Genomics. 11, 434. https://doi.org/10.1186/1471-2164-11-434

Ficetola, G.F., Pansu, J., Bonin, A., 2015. Replication levels, false presences, and the estimation of presence/absence from eDNA metabarcoding data. Mol. Ecol. Resour. 15, 543-556. https://doi.org/10.1111/1755-0998.12338

Foote, A.D., Thomsen, P.F., Sveegaard, S., Wahlberg, M., Kielgast, J., Kyhn, L.A., Salling, A.B., Galatius, A., Orlando, L., Gilbert, M.T.P., 2012. Investigating the potential use of environmental DNA (eDNA) for genetic monitoring of marine mammals. PLOS. ONE. 7, e41781. https://doi.org/10.1371/journal.pone.0041781

Hendry, A.P., Lohmann, L.G., Conti, E., Cracraft, J., Crandall, K.A., Faith, D.P., Häuser, C., 2010. Evolutionary biology in biodiversity science, conservation, and policy: a call to action. Evolution. 64, 1517-1528. https://doi. org/10.1111/j.1558-5646.2010.00947.x

Ishige, T., Miya, M., Ushio, M., Sado, T., Ushiodae, M., Maebashie, K., Yonechie, R., Lagan, P., Matsubayashie, H., 2017. Tropical-forest mammals as detected by environmental DNA at natural saltlicks in Borneo. Biological. Conservation. 210, 281-285. https://doi. org/10.1016/j.biocon.2017.04.023

Janecka, J.E., Munkhtsog, B., Jackson, R.M., Naranbaatar, G., Mallon, D.P., Murphy, W.J., 2011. Comparison of noninvasive genetic and camera-trapping techniques for surveying snow leopards.Journal of Mammalogy.92, 771-783. https://doi.org/10.1644/10-MAMM-A-036.1

Karlsson, A.O., Holmlund, G., 2007. Identification of mammal species using species-specific DNA pyrosequencing. Forensic. Sci.Int. 173, 16-20. https://doi.org/10.1016/j. forsciint.2007.01.019

Lee, R.J., Gorog, A.J., Dwiyahreni A., Siwu, S., Riley, J., Alexander, H., Paoli, G.D., Ramono, W., 2005. Wildlife trade and implications for law enforcement in Indonesia: a case study from North Sulawesi. Biological. Conservation. 123, 477-488. https://doi. org/10.1016/j.biocon.2005.01.009

Margono, B.A., Potapov, P.V., Turubanova, S., Stolle, F., Hansen., M.C., 2014. Primary forest cover loss in Indonesia over 2000-2012. Nature. Climate. Change. 4, 730-735. https://doi.org/10.1038/nclimate2277

Melton, T., Holland, C. 2007. Routine forensic use of the mitochondrial 12S ribosomal RNA gene for species identification. J. Forensic Sci. 52, 1305-1307. https:// doi.org/10.1111/j.1556-4029.2007.00553.x

O'Brien, T.G., Kinnaird, M.F., 1996. Changing populations of birds and mammals in North Sulawesi. Oryx. 30, 150156. https://doi.org/10.1017/S0030605300021530

Qu,C., Stewart, K.A., 2017.Comparing conservation monitoring approaches: traditional and environmental DNA tools for a critically endangered mammal. Peer. J. Preprints. 5, e2828v1. https://doi.org/10.7287/peerj. preprints.2828v1

Robin, E.D., Wong, R., 1988. Mitochondrial-DNA molecules and virtual number of mitochondria per cell in mammalian-cells. J. Cell. Physiol. 136, 507-513. https://doi.org/10.1002/jcp.1041360316 
Rognes, T., Flouri, T., Nichols, B., Quince, C., Mahé, F., 2016. VSEARCH: a versatile open source tool for metagenomics. Peer. J. 18, e2584. https://doi. org/10.7717/peerj.2584

Seguritan, V., Rohwer, F., 2001. FastGroup: a program to dereplicate libraries of $16 \mathrm{~S}$ rDNA sequences. BMC Bioinformatics. 2, 9. https://doi.org/10.1186/14712105-2-9

Schloss, P.D., Westcott, S.L., Ryabin, T., 2009. Introducing mothur: Open-source, platform-independent, community-supported software for describing and comparing microbial communities. Applied and Environmental Microbiology. 75, 7537-7541. https:// doi.org/10.1128/AEM.01541-09

Springer, M.S, Douzery, E., 1996. Secondary structure and patterns of evolution among mammalian mitochondrial 12S rRNA Molecules. J. Mol. Evol. 43, 357-373. https://doi.org/10.1007/BF02339010

Strickler, K.M., Fremier, A.K., Goldberg, C.S., 2015. Quantifying effects of UV-B, temperature, and $\mathrm{pH}$ on eDNA degradation in aquatic microcosms. Biological Conservation. 183, 85-92. https://doi.org/10.1016/j. biocon.2014.11.038
Taberlet, P., Coissac, E., Hajibabaei, M., Rieseberg, L., 2012. Environmental DNA. Molecular Ecology. 21, 1789-1793. https://doi.org/10.1111/j.1365-294X.2012.05542.X

Ushio, M., Fukuda, H., Inoue, T., Makoto, K., Kishida, O., Sato, K., Murata, K., Nikaido, M., Sado, T., Sato, Y., Takeshita, M., Iwasaki, W., Yamanaka, H., Kondoh, M, Miya, M., 2016. Environmental DNA enables detection of terrestrial mammals from forest pond water. Mol. Ecol. Resour. 17, 63-75. https://doi.org/10.1111/17550998.12690

Whitten, A,J., Bishop, K.D., Nash, S.V., Clayton, L., 1987a. One or more extinctions from Sulawesi, Indonesia? Conservation Biology. 1, 42-48. https://doi. org/10.1111/j.1523-1739.1987.tb00007.x

Whitten, A.J., Mustafa, M., Henderson, G.S., 1987b. Ecology of Sulawesi. Gajah Mada University Press, Yogyakarta. 